\title{
Lucas Alamán. La Conquista de México y el origen de una nueva nación
}

\author{
Luis A. Patiño Palafox
}

I

\section{ntroducción y metodología}

Lucas Alamán, político e historiador mexicano, ha pasado a la historia de nuestro país por ser considerado el padre del conservadurismo mexicano del siglo XIX, acusación que no ha impedido que su obra tanto política como histórica sea considerada fundamental para entender el complicado contexto del México independiente de la primera mitad del XIX.

Sus obras han sido citadas innumerables veces, no obstante de que hay pocos trabajos dedicados específicamente a él, y de éstos la mayor parte han sido realizados por historiadores, dentro de los que hay trabajos muy destacados.

El siguiente trabajo será un acercamiento filosófico al pensamiento novohispano; sobre esta disciplina hay una serie de trabajos enfocados en el siglo XIX, sobre todo en torno al liberalismo y al humanismo novohispano. ${ }^{1}$

Nuestra principal herramienta hermenéutica será el concepto de "tradición"; apoyándonos en los recientes trabajos de Ambrosio Velasco Gómez, quien la define de la siguiente manera:

En términos generales, una tradición intelectual puede entenderse como un entramado de teorías, interpretaciones, prácticas, valores e instituciones que sobre un conjunto de problemas teóricos y prácticos, se desarrollan históricamente a través de controversias internas y externas.

${ }^{1}$ Destacan en esta línea los recientes trabajos de Ambrosio Velasco Gómez, quien ha expuesto y desarrollado en obras como Republicanismo y multiculturalismo y, sobre todo, en La persistencia del humanismo republicano en la conformación de la nación y el Estado en México lo que ha denominado "humanismo republicano", defendiéndolo como una tradición de pensamiento político en México, desde el siglo XVI hasta al menos el XIX. 
Desde la perspectiva de las tradiciones, las obras específicas que se enmarcan en tradiciones definidas están condicionadas por ciertos presupuestos (prejuicios) teóricos, axiológicos, conceptuales e ideológicos, pero al mismo tiempo esas obras contribuyen a la transformación de la tradición. Además, en el ámbito político, las tradiciones no sólo tienen consecuencias en el campo intelectual, sino también en el institucional y práctico. ${ }^{2}$

La utilización de dicho concepto como herramienta de análisis del pensamiento político mexicano resulta sumamente útil para los fines de este trabajo, considerando que la visión de la conquista de México que se mostrará es parte de lo que podemos denominar como tradición conservadora, ${ }^{3}$ más allá de los problemas que la dicotomía liberal-conservador presenta para mostrar las complejidades de la realidad política mexicana del siglo XIX. ${ }^{4}$ El concepto de tradición nos sirve para tender el puente entre trabajos tanto históricos como filosóficos y de historia de las ideas políticas, de acuerdo a las tendencias académicas recientes, en las que la relación entre filosofía, historia y pensamiento político, lejos de ser cosas distintas son cosas que deben verse íntimamente relacionadas.

${ }^{2}$ Ambrosio Velasco Gómez, La persistencia del humanismo republicano en la conformación de la nación y el Estado en México. México, unaM, 2009, pp. 20-21.

${ }^{3}$ En su ensayo "Qué es ser conservador", Michael Oakeshott define al conservadurismo más como una disposición que como una doctrina política, lo que permite presentar un cuadro desde el cual autores como Alamán pueden ser explicados como tendencia política más allá del contenido de su obra. Oakeshott, al plantear el problema de la innovación política -uno de los principales en el México del XIX-, dice que la postura conservadora sería la siguiente: "Así pues, la innovación es indispensable si se requiere que las reglas sigan siendo apropiadas para las actividades que gobiernan. Pero, tal como lo entiende el conservador, la modificación de las reglas deberá reflejar siempre, y jamás obstruir, un cambio de las actividades y las creencias de quienes están sujetos a ellas, y en ninguna ocasión deberán ser tan grandes que destruyan el ensemble. En consecuencia, el conservador no tendrá nada que ver con las innovaciones destinadas a satisfacer situaciones meramente hipotéticas; preferirá aplicar una regla que ha aplicado antes a inventar una nueva" (Michael Oakeshott, "Qué es ser conservador", en El racionalismo en la política y otros ensayos. 1a. reimp. Pról. de Timothy Fuller, trad. de Eduardo L. Suárez Galindo. México, FCE, 2001, p. 397).

${ }^{4}$ Una de las obras que más ha abordado la compleja relación entre las distintas corrientes políticas en el México del siglo XIX es: Erika Pani, comp., Conservadurismo y derechas en la historia de México. México, FCE/Conaculta, 2009. Sobre el ensayo en torno a Alamán incluido en dicha obra ahondaremos más adelante. 
Con el fin de desarrollar esta propuesta hermenéutica para la interpretación de las tradiciones y textos políticos, Ambrosio Velasco recurre a los trabajos de Quentin Skinner, Ricoeur y Gadamer.

Considero que junto a antecedentes como la historia de las ideas, desarrollada a partir de los trabajos de José Gaos y que ha dado pie a trabajos fundamentales para analizar la de historia del pensamiento filosófico mexicano, como lo es Una aproximación a la historia de las ideas filosóficas en México. Siglo XIX y principios del XX (México, UNAM, 1997), esta propuesta en torno a la "tradición" es fundamental para el estudio del pensamiento filosófico mexicano, el cual, dada su propia naturaleza, tiene una constante relación con el contexto histórico.

La obra de Alamán es un ejemplo claro de esto, hasta en los títulos de sus obras, que si bien se presentan a primera vista como ensayos históricos, esto se debe en mucho a la forma de escritura de la época, que aún no distingue tajantemente entre lo filosófico y lo histórico, de hecho, el término "filósofo" lo vamos a encontrar en nuestro autor refiriéndose a los ilustrados franceses, a quienes criticaba como portadores de falsas luces, muy en la línea de Edmund Burke, una de sus mayores influencias intelectuales. Sin embargo, no quiere decir que su pensamiento político no tenga bases o repercusiones filosóficas, sino simplemente que Alamán será parte de una respuesta filosófica antiilustrada, en tanto se funda en una tradición política cuyos principios chocan abiertamente con la idea de la soberanía y la representación popular, amparando sus ideas en la experiencia histórica y la convicción de que eran preferibles las reformas y la evolución natural de las sociedades a las revoluciones, que tanto preocupaban por diversas razones a pensadores como Burke, quien en sus Reflexiones sobre la Revolución francesa dejó delineados algunos aspectos claves del pensamiento político conservador.

Queremos adelantar con esto que el conservadurismo es mucho más que una mera respuesta "reaccionaria" al pensamiento moderno, se trata-al menos en lo concerniente al caso mexicano en la obra de Alamán- de un pensamiento estructurado con conceptos definidos de lo que era la nación -no Estado, concepto que es más bien propio de una tradición contractualista-mexicana, su historia, origen, gobierno e instituciones fundamentales propias, especialmente esto último.

Si la obra de Alamán llegó a ser tan importante, más allá de la crítica o apoyo hacia ella, fue precisamente por la solidez y complejidad que detrás de ella había.

De su producción intelectual, la obra más estudiada del autor ha sido la Historia de Méjico desde los primeros movimientos que prepararon su independencia en el año de 1808 hasta la época presente (1848), una de las más importantes de la época, que ha generado opiniones contundentes en 
torno a la importancia de nuestro autor. Sobre Alamán, afirma Charles A. Hale que "La historia era el arma principal de Alamán y la piedra de toque de lo que podría llamarse filosofía política conservadora en México".5

Y aún más, aunado a esto, Hale afirma también que el análisis del inicio de la Independencia de México realizado por Alamán "sigue siendo el tratamiento patrón del periodo 1810-1821 y nunca ha sido igualado por una versión 'liberal'". 6

Debemos hacer aquí un paréntesis, pues la afirmación de Hale con relación a una filosofía política conservadora nos servirá como preámbulo al análisis de Alamán. En dicha filosofía política veremos que la historia juega un papel de gran importancia al ser uno de los elementos fundacionales de la nación, que no es entendida sin un lenguaje, una religión y una cultura común. En el caso de México, la visión conservadora serán el castellano, el catolicismo y una cultura esencialmente hispánica, heredera de la Conquista de México -a la que la nación mexicana debe su existencia- y del proyecto ecuménico español del siglo XVI.

Para dar cuenta de esta visión, en este trabajo me centraré en las Disertaciones sobre la historia de México (Imprenta de José Mariano Lara, 1844-1849), especialmente en la segunda de ellas, titulada Conquista de Mégico y sus consecuencias, en la que, me parece, Alamán se acerca más a la filosofía de la historia que en cualquiera de sus otras obras; analizando en ésta los hechos políticos de México no de manera descriptiva sino considerando una posible necesidad histórica -aunque su pensamiento histórico es en general providencialista-, y mostrando un criterio más enfocado en las consecuencias de los acontecimientos históricos que en un juicio moral sobre ellos.

Es desde esta perspectiva que analiza la historia de México y la conquista realizada por Cortés, sus consecuencias y su lugar como origen de la nación mexicana; es ésta la parte de su pensamiento que más nos interesa, ya que es precisamente esa visión la que separa a Alamán de otros intelectuales de su época, principalmente de Carlos María de Bustamante, a quien podemos considerar, sin duda, como la antítesis intelectual de Alamán en lo que a la visión del pasado español se trata, ya que mientras Bustamante trató de criticar aquel periodo en todos los aspectos - con excepción de la religión católica-, presentándolo como una época de opresión, Alamán busca mostrar y rescatar los aspectos positivos que la Nueva España pudo haber tenido.

${ }^{5}$ Charles A. Hale, El liberalismo mexicano en la época de Mora (1821-1853). 9a. ed. Trad. de Sergio Fernández Bravo y Francisco González Arámburu. México, Siglo XXI, 1991, p. 20.

${ }^{6}$ Ibid., p. 22. 
Esto lo tuvo que hacer tanto contra la visión liberal y sus pretensiones de partir de un punto cero para la creación del México independiente como contra un conservadurismo de tendencia republicana, como lo era el proyecto político de Bustamante, cuya participación política es reconocida fundamentalmente por su influencia en Morelos. ${ }^{7}$

A partir de esto, podríamos considerar como opuestas -al mismo tiempo que complementarias, ya que tratan el mismo problema, pero lo valoran desde distintos supuestos, ampliando la una a la otra-obras como la Historia de Méjico y las Disertaciones de Alamán con relación al Cuadro histórico de la Revolución mexicana de 1810 , de Bustamante. ${ }^{8}$

Sin embargo, no se trata de visiones inventadas o surgidas desde el comienzo de la Independencia, sino que eran producto de procesos más largos en torno a la identidad nacional criolla y la relación que querían poner con la metrópoli.

El Cuadro histórico de la Revolución mexicana es una fuente fundamental para ver esta tradición, en la que Bustamante culmina el proceso de formación de identidad criolla que alcanzó uno de sus momentos claves en obras como las de los jesuitas expulsados en 1767, siendo la Historia antigua de México de Clavijero ${ }^{9}$ la pieza más importante de este proceso, en el que

${ }^{7}$ Siguiendo esto, veríamos que en el debate político mexicano, en la época de Alamán, se pueden distinguir tres distintas corrientes bien definidas - no obstante aún al interior de ellas pudiera haber diferencias que propiciaran matices, pero no la desintegración de un cuerpo común de ideas fundamentales.

La primera es el liberalismo, a su vez dividido en centralistas y federalistas.

La segunda es el republicanismo, heredero del republicanismo novohispano, que va a diluirse paulatinamente perdiendo influencia frente a los otros dos.

El tercero es el conservadurismo, que empezaba a tomar forma doctrinaria precisamente con la obra de Alamán.

Cada una de estas corrientes se enfrentaría a la historia de México con ópticas distintas, ya fuera ignorando el pasado novohispano o bien retomándolo como base de la nacionalidad, aunque dentro de esta segunda tendencia se veía que había una diferencia clave, esto es, se difería radicalmente en la valoración de los tres siglos de dominio español en América. Insistimos en esto, no se trataba de una cuestión de erudición histórica, sino de fundamentar cada uno de estos proyectos políticos.

${ }^{8}$ En realidad esta tesis podría sostenerse no sólo entre estos dos autores, sino que podríamos considerar a otros, como los liberales, habiendo también una relación entre las obras de todos ellos, ya que fue en sus escritos en los que podemos encontrar el debate público y las interpretaciones de la historia de México que cada grupo político defendía.

${ }^{9}$ La obra del jesuita llega a ser tan importante en este aspecto que la visión que del indio se tuviera entre la élite mexicana variaba según fuera el origen de ella: Clavijero o autores como Robertson o de Paw. Eso tendría otra importante repercusión, ya que las políticas liberales hacia la cultura indígena se sustentarían en estas posibles visiones, siendo ésta una de las principales conclusiones de Hale en El liberalismo mexicano en 
se veía claramente la identificación criolla con los antiguos mexicanos, y no con la Conquista ni con España, rompiéndose paulatinamente un lazo cultural que en los siglos XVI y XVII aún daba pie a la existencia de términos como "español de América", con el que se identificaba a los nacidos en la Nueva España. ${ }^{10}$

Y no se trataba de opiniones neutrales que pudieran estar exentas de repercusiones, ya que estaban muy lejos de una posible neutralidad. La visión de Bustamante sobre la guerra de Independencia es clara, porque en ella veía la emancipación de tres siglos de opresión española y, en cierta forma, la justa venganza de los mexicanos contra la derrota sufrida por los antiguos mexicanos frente a Cortés. Tampoco era neutral la visión de Alamán, ya que en la visión que tuvieran de la historia de México cada bando se fundaba su respectivo proyecto político, de forma que la historia no era importante por sí misma, sino como elemento argumentativo a favor de una visión de la política mexicana; en este sentido, podríamos decir que se trata de un uso "ideológico" de la historia, aunque, como hemos intentado mostrar, no de un uso falso sino vinculado a un conjunto de presupuestos sobre lo que era la nación mexicana.

Sobresalen en esta visión partes como la siguiente, que aparece en el Cuadro histórico, en donde Bustamante defendía las acciones de los insurgentes en la toma de Guanajuato; ${ }^{11}$ es aquí que Bustamante deja clara su posición respecto a la lucha insurgente:

[...] la pluma cansada de escribir tantas atrocidades se entorpece; démosle una corta tregua, y solo lamentemos la imprudencia de aquel castillo y de los que dieron la voz de... morir ó vencer, y compadezcamos una ceguedad tan fatal que atrajo tantos males sobre nuestra América. ¡Oh! si Guanajuato no hubiera rompido esta lid! [...] ¡Si los españoles hubiesen calculado el estado de sus fuerzas, su impotencia para contener el curso rápido de una nacion que reclamaba con tanta

la época de Mora (1821-1853), concretamente en el capítulo 7, "El liberalismo y el indio".

${ }^{10}$ El debate llegó a ser tan intenso que se discutía sobre cosas de aparente irrelevancia como la forma de escribir México, es decir, si debía ser "México" o "Méjico", lo que tenía más relación con la carga política que eso implicaba que con un problema en sí mismo.

${ }^{11}$ Fue ese mismo evento el que Alamán tomó como ejemplo para criticar la actuación de Hidalgo, considerándolo uno de los más violentos del inicio de la revolución de Independencia, cuyos métodos habrían provocado un baño de sangre tanto por realistas como por insurgentes, consecuencia de la forma en que se había perdido el control del movimiento cuando Hidalgo lo dirigió. 
justicia su libertad, qué diferente fuera nuestra suerte! Romper con un pueblo, muy poco cuesta; pero reconciliarse con él, restaurar y consolidar una amistad borrada por el odio... establecer una relacion íntima de hermanos, y tornar a amigos y enemigos en una sola familia, es cosa dificilí[si]ma; tales fueron las reflexiones que debieron hacer los que fueron requeridos con la paz.

Como yo he visitado estos lugares, la relacion que acabo de hacer á V. dejó grabada en mi alma una sensacion dolorosísima y profunda luego que la escribí: tan cierto es que la imaginacion domina la mayor parte de nuestros afectos y sentimientos. Sorprendióme el sueño meditando sbre ella, y se me figuró que veía entre aquellos cadáveres y miembros palpitantes, á los genios de Cortés, de Alvarado y de Pizarro, que se mecian despavoridos observándolos, y que lanzándose llorosa sobre ellos la América con voz terrible les decia... ¿De qué os horrorizais á vista de las víctimas? ¿Habeis olvidado las crueles matanzas que hicísteis tres siglos há en Tabasco, en Cholula, en el tempo mayor de México, en Cuernavaca? [...] ¿Ignorais acaso que en la balanza del gran Teotloquenahuaque se pesaron estos crímenes, y que reservó su venganza para mis abatidos y esclavizados hijos, despues de tres centurias de años? ${ }^{12}$

Se definían así dos tendencias opuestas: ${ }^{13}$ el hispanismo ${ }^{14}$ y el indigenismo histórico, con Alamán como claro representante de la primera.

${ }^{12}$ Carlos María de Bustamante, Cuadro histórico de la Revolución mexicana, 5 vols. México, Instituto Cultural Helénico/FCE, $c 1985$, vol. 1, pp. 41-42.

${ }^{13}$ Resulta muy esclarecedora de esta época y de la conformación de los diversos grupos sociales de la Nueva España la obra El proceso ideológico de la revolución de Independencia, de Luis Villoro, que analiza cómo se van separando los bandos y, sobre todo, la forma en que, una vez lograda la independencia, en la parte legislativa y constitucional va disminuyendo el peso del indigenismo y la base popular que podríamos encontrar en el movimiento de Hidalgo y Morelos; la independencia aparece así como un movimiento heterogéneo, el mismo criollismo no era unívoco y es de esta heterogeneidad que van a surgir las corrientes políticas en el México independiente.

${ }^{14}$ Una obra con profunda relación con este tema en el pensamiento político de Alamán es la de Salvador Méndez Reyes, El hispanoamericanismo de Lucas Alamán (1823-1853). México, Universidad Autónoma del Estado de México, 1996.

Pero debemos aclarar que por hispanismo no nos estamos refiriendo aquí a la postura política que sustentó el franquismo, sino que en el siglo XIX definía una postura conservadora que no buscaba una ruptura tajante con lo que a nivel cultural se había construido durante la Nueva España, en esta postura se reconocía la importancia de aspectos como el religioso, lingüístico, político y cultural en la formación de una tradición novohispana, que no debía desaparecer completamente con la emancipación de España. 


\section{Las Disertaciones de Alamán}

Expuesto lo anterior, podemos pasar directamente a Alamán. Las Disertaciones juegan un papel fundamental para comprender el lugar que dentro del pensamiento de Alamán tenía la historia, en concreto de México, aunque no por ello dejó nuestro autor de analizarla en un sentido universal, sobre todo si consideramos su interés en la formación y caída de imperios y la relación de esto con el desarrollo de la civilización. Además, el objetivo de sus obras era distinto según el caso, si bien encontramos en él ideas constantes, ya sea en la Historia de Méjico o las Disertaciones, lo mismo en otros textos menos conocidos pero claves para ver el núcleo duro de su pensamiento en torno a la política del México independiente ${ }^{15}$ podríamos decir que el objeto de análisis de la Historia de Méjico es la guerra de Independencia y de las Disertaciones el origen de la nacionalidad mexicana, además de que en ellas profundiza varios de sus puntos de vista sobre el virreinato. Elías Palti considera que "Alamán no se propuso nunca presentarnos en su Historia de Mégico una genealogía de la nacionalidad. En todo caso, si éste era el proyecto original de sus Disertaciones, compuestas inmediatamente antes de la guerra con Estados Unidos, esto es, develar la constitución de la nacionalidad mexicana rastreándola en su génesis histórica [...] él mismo ya había sucumbido". ${ }^{16}$

Nuestro autor distinguía la historia mexicana de la historia universal, siendo la segunda su criterio de análisis, por lo que sus reflexiones pretendían insertar la historia mexicana en la historia mundial. Alamán tuvo una sólida formación en estudios y obras históricas, siendo conocedor tanto de autores clásicos como de modernos, por lo que era evidente que una de sus principales preocupaciones intelectuales era precisamente la historia, a la que concebía no como un saber válido por erudición, sino más bien por su utilidad para la vida humana y, sobre todo, por sus enseñanzas para la política. Nuestro autor parecía estar así dentro de la corriente moderna de pensamiento que

La lectura que de este aspecto del pensamiento de Alamán se ha hecho desde lo que podemos considerar la filosofia latinoamericana tiende a ver en Alamán al defensor de una unidad cultural de los países que surgieron de la disolución de la monarquía española una vez lograda la independencia de sus antiguas colonias. En nuestra opinión, el libro de Méndez Reyes es una clara muestra de esta lectura de Alamán.

${ }^{15}$ Un buen ejemplo de esto son textos como la Defensa del ex ministro de Relaciones don Lucas Alamán o el Examen imparcial de la administración del general vicepresidente don Anastasio Bustamante (Lucas Alamán, Documentos diversos (inéditos $y$ muy raros). México, Jus, 1946, t. III o en edición reciente, en 2008 por Conaculta).

${ }^{16}$ Elías Palti, "Lucas Alamán y la involución política del pueblo mexicano. ¿Las ideas conservadoras 'fuera de lugar'?", en E. Pani, coord., Conservadurismo y derechas en la historia de México, t. I, p. 315. 
vemos con más claridad en el siglo XVI, en el que la historia era considerada como la maestra de la vida, siendo Maquiavelo el principal representante de esta comprensión de la historia.

De fondo, la idea que subyace a esta idea de la historia es que los acontecimientos humanos se presentan con cierta periodicidad, de forma que hay leyes constantes que la permean, a pesar de que los eventos no sean en esencia los mismos, sino que más bien se conciben ciertas analogías entre un evento y otro, de tal manera que la comprensión de uno de ellos, el anterior, puede ser una guía para las acciones a seguir en el segundo. Esta misma concepción es la que permitía a Alamán hacer una analogía entre dos eventos distintos como eran la Revolución francesa y la guerra de Independencia, y aplicar las reflexiones de Burke en torno a los eventos de 1789 a la revolución iniciada por Hidalgo en 1808.

Volvamos a la división inicial entre historia mundial e historia nacional. Desde este punto de partida, Alamán consideraba que la Conquista y la Independencia de México habían sido los dos eventos de la historia mexicana que habían tenido más relevancia en la historia universal, y de manera concreta, la primera era fundamental como origen del régimen colonial. Alamán consideraba que la Conquista había sido estudiada, pero no en el sentido que a él le interesaba, esto es, como base del establecimiento del gobierno virreinal, intención clara si consideramos que quería defender a dicho régimen del olvido y la condena en que el México independiente - la visión liberal y republicana- lo quería poner como consecuencia inevitable de la necesidad de formar un nuevo Estado.

Esto debe ser analizado, ya que muestra el contexto mexicano de la época y las luchas ideológicas que se dieron por diferencias que son muy notorias si leemos paralelamente las distintas obras -en su mayoría históricas, siguiendo los modos intelectuales de la época- de ese tiempo, en las que el régimen novohispano era visto de maneras muy distintas. A esto debemos agregar que otro punto en común en ellas era que partían del año 1808 para los análisis sobre la Independencia de México, habiendo un acuerdo común de que a pesar de que el movimiento insurgente comenzó en 1810, sus raíces estaban en las juntas llevadas a cabo en 1808 por el Ayuntamiento de México. ${ }^{17}$

${ }^{17}$ Por supuesto, como otros autores -Zavala o Mora, por ejemplo-, Alamán tiene perfecta conciencia del parteaguas que fue el año 1808 con la invasión francesa a España y la crisis consecuente gubernamental, pero a diferencia de los autores citados, no considera que la historia "interesante" -adjetivo utilizado por Zavala- de México hubiera empezado en ese año sino que, por el contrario, la construcción del México independiente era inconcebible sin tener en cuenta los logros y beneficios de los casi tres siglos de dominación española. 
Alamán tenía un balance positivo sobre el virreinato, mostrando abiertamente su oposición a la forma en que fue realizada la Independencia en sus primeros años, siendo la figura de Hidalgo fuertemente atacada por Alamán, que consideraba que en esa lucha se había destruido lo mejor del régimen novohispano, siendo el México independiente incapaz de lograr una organización política estable, y ya no se diga, de crear una sociedad-mejor a la prehispánica, en su opinión- como sucediera en el siglo XVI bajo el liderazgo de Cortés y el traslape del mundo hispánico de ese siglo al Nuevo Mundo.

Diversos momentos de las Disertaciones son una crítica mordaz al régimen político mexicano del siglo XIX desde la comparación con el mundo del siglo XVI, como se puede ver en sus análisis sobre la fundación de la ciudad de México o cuando analiza la obra política e institucional de Cortés.

El punto anterior en torno a las analogías entre el siglo XVI y el XIX toca un aspecto fundamental que aparece en la Historia de Méjico y es la disputa que se nos hace evidente, enfrentamiento por definir a los héroes de la nueva patria y con ello quién detentaba su paternidad. Alamán se enfrentaba abiertamente a la idea de que la figura de Hidalgo fuera la fundadora del México independiente y, por lo contrario, pedía un debido reconocimiento a Iturbide, que había logrado la independencia en poco tiempo y con lo que para Alamán era un proyecto político que incluía a todos los miembros de la sociedad mexicana, con esto se refería al Plan de Iguala. ${ }^{18}$

Debemos notar que si unimos la Historia de Méjico y las Disertaciones, se evidencia que Alamán intentó escribir y analizar la historia de México en su totalidad hasta su época, partiendo de la Conquista como inicio y abarcando sucesivamente varios aspectos del mundo virreinal; todo esto tiene sentido

${ }^{18}$ Se trata de una consecuencia del pensamiento de Alamán, ya que el proyecto de independencia de Iturbide era el más acorde a la visión de la nación que profesaba nuestro autor. El Plan de Iguala era no sólo una transición relativamente pacífica de la dependencia a la libertad política, de acuerdo a los principios esencialmente reformistas que planteaba Burke, contrarias a las revoluciones. Hay además otras razones de la aprobación de Alamán hacia el Plan de Iguala, dos que deben destacarse son la idea de que la separación de la Nueva España se veía como una separación natural, como la de la madurez de un hijo que deja a sus padres, siendo esta imagen la que el Plan exponía. Para el tema de la nación esto es fundamental, ya que significaba la continuidad de la herencia cultural hispánica en el México independiente, es decir, la separación no se haría contra España, sino como una especie de maduración de lo que España había cimentado en el Nuevo Mundo; una segunda es la idea de una separación no guiada por principios populistas - no obstante, una vez hecho emperador, Iturbide avaló la existencia de un congreso- sino por lo que para el lenguaje de la época era considerado como la "gente de bien". Estos elementos son parte de los principios clave de la tradición conservadora, a tal punto que su esencia se mantendrá en el XIX y cuestiones como la paternidad de la patria serían objeto de controversia en espacios como la prensa. 
al ver que para Alamán, lo que era México había tenido su origen en la Conquista y en la hispanización de América; para él, el mundo indígena tenía un papel secundario y no busca fundar la mexicanidad en él, ${ }^{19}$ como sí lo hacía Carlos María de Bustamante. ${ }^{20}$ Las intenciones de nuestro autor quedan claramente expuestas en el siguiente texto:

El objeto que me propongo en estas disertaciones es examinar los puntos mas importantes de nuestra historia nacional, desde la época en que se estableció en estas regiones el dominio español, es decir, desde que tuvo principio la actual nacion megicana y seguir á esta en sus diversas vicisitudes, hasta el momento en que vino á constituirse en nacion independiente. Ningun estudio puede ser mas importante que el que nos conduce á conocer cual es nuestro orígen, cuales los elementos que componen nuestra sociedad, de donde dimanan nuestros usos y costumbres, nuestra legislacion, nuestro actual estado religioso, civil y político: por qué medios hemos llegado al punto en que estamos y cuales las dificultades que para ello ha habido que superar. ${ }^{21}$

Alamán iba más lejos y consideraba no sólo la historia de México, sino que a partir de la España de los Reyes Católicos hace una conexión entre las Cruzadas y la reconquista de España. Pensaba que la lucha contra los infieles había sido una característica de los pueblos europeos, viendo en estas luchas una de las causas de la conquista de América, ya que este espíritu bélico era el que tenían los españoles al venir a América. ${ }^{22}$ Esto es claro al leer, por ejemplo, las Cartas de relación de Cortés, en que la mentalidad caballeresca del conquistador de México era evidente; sobra mencionar la admiración que por Cortés

${ }^{19}$ Como tampoco lo haría el proyecto liberal, pero por otras razones que emanaban de los presupuestos modernos de los que partían, principios incompatibles con el corporativismo novohispano y con la distinción entre ciudadanos, que en la visión liberal debían ser todos iguales. Vemos así que el conservadurismo ignoraba el indigenismo como algo culturalmente superado por la conquista, mientras que el liberalismo lo hacía por su afán de romper con el pasado novohispano y lo que desde el discurso moderno era oscuridad y atraso. Esta hispanofobia tendría a uno de sus principales voceros en Lorenzo de Zavala.

${ }^{20}$ Y no sólo autores como Bustamante sino que fue una clara tendencia en el siglo $\mathrm{xx}$ con el proyecto nacionalista, como también indica Hale en la obra ya mencionada.

${ }^{21}$ Lucas Alamán, "Primera disertación. Sobre las causas que motivaron la conquista y medios de su ejecución", en Disertaciones sobre la historia de México. Hernán Cortés y la Conquista de México, t. I. 7a. ed., y primera en lo conducente a Hernán Cortés y a la Conquista de México. México, Jus, 1985, p. 7.

${ }^{22}$ A esto que dice Alamán debemos agregar la vocación religiosa, sin la cual no se entendería la formación de la monarquía española. 
sentía Alamán, manifiesta no sólo en esta segunda disertación, sino en otras dedicadas a las fundaciones y aspectos biográficos de aquél.

Es por demás interesante que Alamán viera en las Cruzadas una causa de progreso y de unidad política, con lo que se veía ya su preferencia por un sistema centralizado, ${ }^{23}$ afirmando que la época de los Reyes Católicos fue, cito, “¡Dias de gloria y de prosperidad para España, bien diversos de los dias de miseria y de confusion á que la ha traido en los nuestros el desenfreno de las pasiones y el furor de los partidosi Todo entonces prosperaba para ella, y aun sus mismos reveses contribuian á aumentar su poder y su gloria". ${ }^{24}$

Todo esto había sido precedido por la larga guerra de reconquista, que a su vez había sido parte de la lucha contra los infieles, factor histórico muy europeo, aunque especialmente arraigado en los reinos hispánicos, que antes que cualquier otro tuvieron que luchar frontalmente contra los musulmanes, lucha que se mantuvo por siglos hasta terminar en 1492.

Es claro que Alamán sentía apego por esta larga tradición netamente hispánica, ${ }^{25}$ pero su visión no se limitaba a una mera admiración por esa época, sino que se basaba en la idea de que de ella habían venido consecuencias positivas y progreso material, por el que siempre se preocupó, incluso estudiando en Europa cuestiones totalmente aplicables a la economía y especialmente a la minería. Su juicio era que el siglo XVIII -Siglo de las Luces-, con una actitud "impía", había desacreditado las Cruzadas, pero que en el XIX, aquéllas, "mejor examinadas por los escritores imparciales y profundos de nuestros días, son miradas como una de las causas que más contribuyeron al desarrollo de la inteligencia humana, á la estabilidad y regularidad de los gobiernos y á los adelantos de la geografía y el comercio". ${ }^{26}$

En este aspecto es en donde se hace notoria la gran influencia de Edmund Burke sobre Alamán, la cual fue reconocida por el segundo. Alamán se muestra igualmente crítico de los principios de la filosofía política ilustrada y lo que consideraba como meros planteamientos abstractos, confrontando con ellos

${ }^{23}$ Se trata de algo fundamental en su pensamiento político y aparece a lo largo de su obra, pero es mucho más claro en su Examen imparcial de la administración del vicepresidente don Anastasio Bustamante, de la que fue funcionario y defensor.

${ }^{24}$ L. Alamán, "Primera disertación. Sobre las causas que motivaron la Conquista y medios de su ejecución", en op. cit., p. 14.

${ }^{25}$ En este caso, la de la España imperial y el proyecto ecuménico que alcanzó su cenit con el reinado de Carlos $\mathrm{V}$, en el que se dieron las disputas más fuertes en torno a la legitimidad del Imperio español. Sobre esto abundaremos más adelante.

${ }^{26}$ L. Alamán, "Primera disertación. Sobre las causas que motivaron la Conquista y medios de su ejecución”, en op. cit., p. 11. 
la tradición, fuente de saber político e histórico. ${ }^{27}$ En este caso, a Alamán le importa tener en su justa dimensión la tradición creada o insertada en México por la Conquista, cuya pérdida significaba para él estar en una especie de limbo identitario.

Pero debemos avanzar más en la exposición. Alamán, en la Segunda disertación, muestra una visión claramente providencialista de la historia, e incluso, aunque no plenamente desarrollada, una teoría de los imperios y una crítica a la antropofagia de los pueblos prehispánicos y a su estado previo a la Conquista. Se trata de un tema fundamental en el siglo XVI, en el que se discutió la legitimidad de la conquista de América por España, la que era defendida por Alamán desde una visión a posteriori, por decirlo así, ya que a él no le interesaba tanto la justicia de esa guerra como los resultados que trajo, siendo el principal de ellos el surgimiento de la Nueva España, ${ }^{28}$ que el propio Alamán vio en sus últimos momentos - de apogeo- previos al inicio de la lucha por la independencia, cuyos acontecimientos recordaba con horror a pesar de los años transcurridos entre ellos y la redacción de la Historia de Méjico. El ejemplo más claro de esto es la forma en que analiza a Hidalgo, criticando su falta de método, el desorden que provocó y que, en opinión de Alamán, ese movimiento retardó más que ayudó a la consecución de la independencia.

${ }^{27}$ Burke había afirmado algo que marcó el pensamiento de Alamán en relación con las revoluciones y la innovación, dejando un escepticismo muy fuerte en torno a los principios ilustrados. Cito a Burke: "La ciencia de construir una comunidad, de renovarla o de reformarla, no puede, como ninguna otra ciencia experimental, enseñarse $a$ priori. No es tampoco una breve experiencia la que nos puede enseñar es ciencia práctica, porque los efectos reales de las causas morales no son siempre inmediatos; [...] La ciencia del gobierno que es, en consecuencia, práctica en sí y dirigida a tales propósitos, es materia que exige experiencia e incluso más experiencia de la que puede alcanzar en toda su vida una persona, por sagaz y observadora que sea; por ello sólo con precaución infinita es posible aventurarse a derribar un edificio que ha respondido en proporción aceptable durante siglos a las finalidades comunes de la sociedad" (Edmund Burke, "Reflexiones sobre la Revolución francesa", en Textos políticos. 2a. reimp. Trad. de Vicente Herrero. México, FCE, 1996, pp. 93-94).

${ }^{28}$ Indirectamente, Alamán retoma el tema que en la disputa de Valladolid fue tratado por Ginés de Sepúlveda, esto es, la legitimidad del Imperio español como una empresa civilizadora. Eran las mismas cosas de las culturas prehispánicas las que criticaban Ginés de Sepúlveda y Alamán, esto es, la antropofagia, si bien es cierto que Alamán trataba de darle una explicación y no sólo de enjuiciarla, como veremos más adelante. Sin embargo, en Alamán se ve también la idea de la superioridad de la cultura hispánica y de que la conquista había traído a los pueblos originarios una civilización superior a la que tenían antes, de hecho, desde la óptica de Alamán, ni siquiera se podría considerar que dichos pueblos fueran lo civilizados y admirables que narraban las crónicas, mostrando juicios muy fuertes en torno al desarrollo de esos pueblos. Alamán nunca cita a Sepúlveda -su obra se publicó después y no es posible que haya tenido acceso a ella-, mas las ideas en torno a la civilización son muy similares. 
Entramos con eso a uno de los puntos fundamentales de esta presentación, pues vemos así la relación de Alamán con el mundo indígena y la Conquista, con todo lo que esto ha significado para la historia mexicana y las inevitables luchas ideológicas que este acontecimiento ha ocasionado.

Alamán, hombre de amplia cultura, conocía la obra de los misioneros del siglo XVI y en general la historia novohispana, así como también a autores de su época, tanto novohispanos como mexicanos y extranjeros; esto hace más clara su postura frente al pasado indígena, que fue derrotado, dejando su lugar al mundo novohispano; y por ello, muestra Alamán una perspectiva menos moralizada de la historia, incluso más pragmática, y podríamos decir que en cierta forma acepta necesidades superiores en ella, de manera que no deberíamos de ver los aspectos negativos, sino ver lo que a partir de esos acontecimientos se construye.

Así, para Alamán, la Conquista y España eran la base de todo lo que constituye a México. El autor de la Historia de Méjico, distaba de halagar a las sociedades indígenas y se mostraba en franco desacuerdo con la antropofagia practicada por algunas de ellas, consideraba Alamán que, en sentido estricto, no se puede hablar de sociedad en un lugar en donde los hombres se comían unos a otros, con lo que tocaba de manera rápida uno de los temas más debatidos por los teólogos y juristas españoles del siglo XVI. ${ }^{29}$

Alamán no profundiza en este tema, pero indirectamente se mete a otro de gran importancia como lo es el juicio sobre la civilización de las sociedades indígenas, con lo que se hace evidente que no le parecían especialmente desarrolladas, ya que según él se habían obtenido muchos beneficios por la Conquista y la evangelización realizada por los misioneros del XVI -sobre todo beneficios materiales-, a quienes considera entre los grandes benefactores de la historia de México y de los indios. Afirma que:

Con la religión [los españoles] les enseñaron también las artes más necesarias á la vida civil y dieron principio á la industria á que la Nueva España debió su grandeza y prosperidad. [...] Estos esfuerzos en beneficio de la humanidad, no fueron el resultado de principios filosóficos,

${ }^{29}$ En especial, la Escuela de Salamanca, fundada por Francisco de Vitoria, que llega a América con fray Alonso de la Veracruz, quien retomaría los argumentos desde la ley natural para defender la validez de las culturas prehispánicas y su libre determinación política. Esto no hace sino mostrar que las polémicas del siglo Xvi tuvieron repercusión en la construcción de la nación mexicana en el siglo XIX, en tanto las ideas discutidas en esa época sirvieron como base para sustentar aspectos específicos de la nacionalidad, en este caso, su origen. 
sino únicamente el efecto de la caridad cristiana, cuyo más glorioso triunfo ha sido la civilizacion de todo el nuevo continente $[\ldots]^{30}$

En el caso de los indígenas de su época, poco cambiaba su opinión, pero debe decirse que en general no sentía gran interés teórico por las clases bajas mexicanas, a pesar de lo cual hacía interesantes comparaciones entre ellas, llegando a mencionar a los negros, a quienes consideraba como una clase productiva a la que se había menospreciado desde los tiempos de la sociedad novohispana, y aún más, en las comparaciones entre ellos y los indígenas el juicio de Alamán es más halagador hacia los primeros, a quienes consideraba más activos e incluso más valientes que los indígenas, recordando peleas en las que habían muerto tanto el negro como el criollo o su rival en turno.

La parte más importante de la Segunda disertación viene casi al final de ella, siendo un escrito del mayor interés que debe verse con más detalle, apareciendo tal vez lo más complejo del pensamiento de un Alamán más cerca de la filosofía de la historia que de la crónica histórica.

Viene ahora lo que arriba considerábamos como una teoría de los imperios, y vemos que Alamán iba más atrás de su tiempo y comenzaba su análisis con el Imperio romano. Aquí, de nuevo, expone un criterio no moral, sino más bien uno pragmático e incluso, podríamos decir, progresista, ya que Alamán mostraba un gran interés por la expansión de la civilización, para lo cual aceptaba la necesidad de la guerra y de la violencia siempre que esos medios, a primera vista criticables, llevaran después a resultados elogiables.

Alamán parte para su análisis del Imperio romano, como hemos dicho, y considera que esta lógica de dominio de los pueblos fuertes sobre otros débiles -que fue muy bien vista por los autores clásicos romanos y griegos, que él conoció-, una vez aplicada por los romanos sobre pueblos a los que no tenían razón de conquistar, fue el origen de las naciones modernas. En otras palabras, debemos ver las conquistas más allá de la moral y considerar primero sus resultados, centrarnos más en la razón progresista que en juicios morales.

Afirma Alamán que:

[...] las naciones modernas deben todas su orígen á esta serie de invasiones, y la providencia divina, que por arcanos que nosotros no podemos penetrar, sabe sacar el bien del mal, ha hecho que por esta serie

${ }^{30}$ L. Alamán, "Séptima disertación. Establecimiento y propagación de la religión cristiana en la Nueva España", en Disertaciones sobre la historia de la República mexicana. Antología y estudio introductorio de Leopoldo Solís y Guillermina del Valle. México, Conaculta, 1991, pp. 202-203. 
de acontecimientos el estado social se mejore y las luces y los conocimientos se extiendan. ${ }^{31}$

Más adelante diría que: "La conquista de los romanos unió todas las naciones conocidas bajo unas mismas leyes, les dió una misma lengua y por este medio la civilizacion se generalizó y se facilitó el camino al establecimiento del cristianismo".32

Esto es, había sido fundamental para la unidad cultural europea, que admiraba, y que en su época se concebía ya como una cultura común. Alamán utilizó la misma lógica para analizar la Conquista de México como un acontecimiento de relevancia universal y guiado por las mismas reglas que las demás conquistas, apareciendo algunas de las consideraciones más relevantes de nuestro autor, ya que en su visión, todo lo que era México venía de esa Conquista y eso es lo que debía ser tomado en cuenta en vez de los males que había causado, pues en su opinión: "El camino del conquistador no puede quedar trazado sino con sangre, y todo lo que hay que examinar es, si esta se derramó sin innecesaria profusion y si los bienes succesivos han hecho cerrar las llagas que la espada abrió". 33

Pero Alamán analizaba esto desde una visión muy definida de los indígenas y su cultura, considerando algunos de sus aspectos más polémicos y que habían sido objeto de análisis desde el descubrimiento de América.

El primero de ellos era el de los sacrificios humanos, que si bien criticaba, también analizaba tratando de encontrar sus razones más allá de un criterio de barbarie como se hizo en el siglo XVI -el mejor ejemplo de esto fue la postura del ya mencionado Ginés de Sepúlveda. Es evidente que Alamán no podía aceptar los sacrificios humanos, y de hecho es lo que más criticaba de esas sociedades, pero también intentaba dar una explicación histórica a dicho fenómeno, sobre todo por las carencias técnicas de los pueblos americanos, consideraba Alamán que antes de la Conquista los indígenas estaban en la miseria respecto a las comodidades propias del uso del fierro, el acero y en las máquinas hechas con ello, así como de otros beneficios derivados de estos instrumentos.

Como hemos dicho antes, la consideración sobre los sacrificios era dura, afirmando que "tales sacrificios era ciertamente un obstáculo insuperable

${ }^{31}$ L. Alamán, "Segunda disertación. Conquista de Megico y sus consecuencias", en Disertaciones sobre la historia de México. Hernán Cortés y la Conquista de México, t. I. 7 a. ed., y primera en lo conducente a Hernán Cortés y a la Conquista de México. México, Jus, 1985, p. 103.

${ }^{32}$ Idem.

33 Ibid., p. 104. 
para todo adelanto verdadero en la civilizacion, pues no puede haber sociedad entre gentes que se comen unas á otras", ${ }^{34}$ encontrando Alamán en esto una diferencia fundamental con el cristianismo, que, efectivamente, había tenido sus historias de crueldad, pero no eran ni su esencia ni su fondo religioso.

Era entonces que Alamán exponía lo que consideraba las ventajas y logros del régimen virreinal instaurado a partir de la Conquista e incluso afirmaba que lo mejor había sido que, de entre los distintos países europeos que se repartieron América, fuera España el que dominó México, ya que a las colonias españolas "no se las consideró meramente como establecimientos productivos, sino que se las hizo partícipes de todo cuanto habia en la metrópoli. [...] Los monarcas españoles, profundamente religiosos ante todo, consideraron la propagacion de la religion [...] y con la religion vinieron todos los beneficios de la sociedad civil". ${ }^{35}$

Alamán consideraba que este juicio debía aceptarse si se hacía de forma imparcial y con una crítica severa sobre el pasado novohispano, pero sabemos que lejos de que se analizara fríamente el virreinato, las obras escritas mostraban profundas luchas ideológicas y visiones opuestas del dominio español en América, la visión de la lucha de Independencia y la forma en que el México independiente debía ser gobernado, temas centrales de la discusión política del México decimonónico.

Llegamos así a una de las conclusiones más importantes de Alamán, ya que en ella se veía claramente el uso fundacional que quería hacer de la conquista para la formación de la nueva nación mexicana, y por que consideraba a España como "una nacion que en aquella época era la primera de la Europa, cuyas armas eran respetadas por todas las demas naciones, en todo el esplendor de su literatura y de sus artes", ${ }^{36}$ por su parte, los indígenas habían sido pueblos guerreros que habían defendido su libertad con heroísmo, dando esta mezcla a la nación mexicana un origen noble y glorioso, que no habían tomado en cuenta quienes consideraban justa la Independencia por la injusticia de la Conquista, y con ello, creía Alamán, dejaban sin patria a dos terceras partes de los habitantes de México.

La relación con España, después de la Independencia, encontró otros defensores que tuvieron una clara influencia de las ideas de Alamán, autores que igualmente tomaron la Conquista de México como origen de la mexicanidad y que buscaban defender la herencia e importancia del virreinato en la conformación de lo mexicano. Pasamos ahora a ver a algunos de estos autores.

${ }^{34}$ Ibid., p. 106.

35 Ibid., p. 107.

${ }^{36}$ Ibid., p. 109. 


\section{La herencia de Alamán}

Alamán ha sido uno de los autores más citados y referidos al estudiar el siglo XIX, no obstante, como hemos dicho, son pocos los trabajos dedicados en específico a su persona. A pesar de esto, la influencia de sus ideas ha sido clara en la conformación del llamado conservadurismo, por lo que algunas de sus ideas centrales terminarían por determinar una corriente de pensamiento político en nuestro país.

Su influencia es tal vez más evidente en José Vasconcelos que en cualquier otro autor -él mismo se veía como un Alamán-; se trata de uno de sus principales estudiosos y apologistas, ya que para él, como lo fue antes para Alamán, la fundación del México independiente no podía pasar por alto el pasado colonial, sin el cual quedaba incompleta la radiografía cultural de nuestro país. Sin embargo, lejos de superar las acaloradas luchas ideológicas, la visión de Vasconcelos estaba igualmente cargada de ideas personales que desembocaban en una postura filosófica que enfrentaba a lo largo de distintos momentos históricos el hispanismo con el mundo protestante, fundamentalmente sajón y de ideas liberales, con las que el propio Vasconcelos estaba enfrentado, si bien su idea central en La raza cósmica era la de promover una raza y cultura que integrara lo mejor de todas las que le habían precedido.

Dentro de esta corriente, Toribio Esquivel Obregón muestra una relación clara con este conservadurismo, tan evidente como la de Vasconcelos, publicando en 1939 un libro producto de una serie de conferencias sobre Cortés, dictadas en la Sociedad de Geografía y Estadística en 1934, narrando los problemas para la publicación y sobre todo lo políticamente incorrecto que era defender la figura del conquistador español. La obra, finalmente publicada con el título Hernán Cortés y el derecho internacional en el siglo XVI, nos muestra gran erudición por parte del autor respecto a la historia tanto de España como de México, la que utilizaba hábilmente para defender sus argumentos a favor de la paternidad nacional por parte de Cortés, a quien analizaba desde la obra de Francisco de Vitoria y considerando que en la Conquista de México se había seguido lo estipulado por el fraile salamantino en su relección Sobre los indios, sobre todo la parte dedicada a los títulos legítimos de guerra contra los indios.

Esquivel veía a Cortés como "la figura histórica más grande de las que han pisado el territorio mexicano", ${ }^{37}$ de ahí que considerara que a pesar de las muchas obras ya escritas sobre él, "lejos de ser extraño que nos ocupemos una vez más en la personalidad de Cortés, lo extraño es que en México no se

37 Toribio Esquivel Obregón, Hernán Cortés y el derecho internacional en el siglo XVI. México, Polis, 1939, p. 57. 
haya ocupado la atención de nuestros ciudadanos, como debería hacerlo, en el fundador de la nación mexicana". ${ }^{38}$

La idea por sí misma iba contra el indigenismo histórico, desarrollado sobre todo en el siglo xx, pero el desarrollo que hacía Esquivel era más complejo, remontándose a un análisis del valor de las civilizaciones prehispánicas, tomando una postura sepulvediana, aceptando la conquista de América como medio civilizador, y haciendo juicios abiertamente reprobatorios del mundo precolombino. Esquivel, franco hispanófilo - aunque él considera que sus ideas buscan contribuir a México al ayudarlo a reconocer su origen-, toca temas que, por un lado, nos regresan a las discusiones jurídicas del siglo XVI, que él conocía, y por otro, está abriendo temas que después serán tratados, uno de los más importantes, el de la posibilidad de que hubiera un pensamiento filosófico entre los pueblos prehispánicos, posibilidad que niega tajantemente. A partir de esto, Esquivel afirmaba que:

No; en principio ningún pueblo tiene derecho de conquistar a otro; en principio España no tenía derecho a conquistar el reino de Moctezuma; en principio, los teopisques aztecas tenían derecho a seguir aumentando hasta el infinito el número de las cabezas de los prisioneros devorados que componían el fúnebre tzompantli en los templos indígenas.

Pero, hecha esta concesión en el campo del derecho abstracto, nos encontramos luego con la innegable realidad, de que los pueblos bárbaros y atrasados son invariablemente conquistados por los pueblos más cultos; y a la luz de este hecho, la pregunta no debe ser si España tuvo o no en abstracto el derecho de conquistar esas tierras, sin esa otra: ¿Era preferible, que hiciera la conquista España o que la hubieran hecho los ingleses? ${ }^{39}$

Hemos visto así el antecedente más inmediato del Hernán Cortés. Padre de la nacionalidad, de Vasconcelos, publicado por primera vez en 1941 y con una segunda edición en 1944, esa última mucho más ilustrativa del pensamiento del autor. Esta obra de Vasconcelos, me parece, es menos compleja en su análisis de la historia de México, su valor es, principalmente, el ser testimonio del desarrollo alcanzado por las ideas histórico-filosóficas que Alamán expuso en sus Disertaciones ${ }^{40}$ y de una tradición de pensamiento que, estructurada por Alamán y retomando la historia como argumento, formula

38 Ibid., p. 58.

${ }^{39}$ Ibid., pp. 127-128.

${ }^{40}$ En el prólogo, Vasconcelos hacía algunas reflexiones interesantes sobre la guerra, el imperialismo y lo que ahora llamamos "orden mundial", reflexiones que fueron 
una idea de nación que tiene como base la cultura hispánica. Este proyecto, a pesar de no haber triunfado en el siglo XIX frente al proyecto liberal, mantuvo su presencia de forma marginal hasta el siglo $\mathrm{xx}$, en que hemos localizado intelectuales que defendían esta tradición, surgida de una interpretación propia de la historia mexicana.

\section{Conclusiones}

Este espacio es insuficiente para analizar detalladamente la compleja época en la que vivió Alamán o su obra, que requiere un análisis propio y amplio, revisando su conjunto y su relación con otros autores. Aquí analizamos sólo parte de sus Disertaciones, problematizando algunas de las cuestiones más relevantes desde el ámbito de las ideas políticas de Alamán en lo relacionado con los orígenes culturales de México y la ideología con la que se pretendió fundar la nación una vez que se logró independizar de España. Las Disertaciones de Alamán son la más clara manifestación del pensamiento conservador en torno al origen de México -o al menos su base-, a la vez que el pensamiento más estructurado de esta tendencia, por lo cual considero que debe ser incluido en un análisis serio sobre la identidad nacional si queremos ir más allá de los tópicos nacionalistas y reduccionistas centrados en la parte indígena del pasado mexicano. Tampoco el conservadurismo es la palabra final sobre este tema tan complejo y siempre abierto a reinterpretaciones, pero es parte fundamental de una época sin la cual no podríamos entender a nuestra nación.

fruto de lo que se veía claramente como un ambiente pesimista ante la Segunda Guerra Mundial. 